\title{
Application of the Linkam TS1400XY heating stage to melt inclusion studies
}

Rosario Esposito ${ }^{1}$, Rita Klebesz ${ }^{1,2}$, Omar Bartoli $^{3}$, Yury I. Klyukin ${ }^{4}$, Daniel Moncada1, Angela L. Doherty ${ }^{1,2,5}$, Robert J. Bodnar ${ }^{1 *}$

1 Virginia Polytechnic Institute \& State University, Department of Geosciences, Blacksburg, 24061, VA, USA

2 Università di Napoli Federico II, Dipartimento di Scienze della Terra, Naples, 80138, Italy

3 Università degli Studi di Parma, Dipartimento di Scienze della Terra, Parma, 43100, Italy

4 Institute of Geology and Geochemistry of Urals Branch, Russian Academy of Sciences, Yekaterinburg, Russia

5 Università degli Studi di Messina, Dipartimento degli Alimenti e dell'Ambiente, Messina, 98166, Italy

Received 4 November 2011 ; accepted 30 January 2012

Abstract: Melt inclusions (MI) trapped in igneous phenocrysts provide one of the best tools available for characterizing magmatic processes. Some Ml experience post-entrapment modifications, including crystallization of material on the walls, formation of a vapor bubble containing volatiles originally dissolved in the melt, or partial to complete crystallization of the melt. In these cases, laboratory heating may be necessary to return the $\mathrm{Ml}$ to its original homogeneous melt state, followed by rapid quenching of the melt to produce a homogeneous glass phase, before microanalyses can be undertaken.

Here we describe a series of heating experiments that have been performed on crystallized MI hosted in olivine, clinopyroxene and quartz phenocrysts, using the Linkam TS1400XY microscope heating stage. During the experiments, we have recorded the melting behaviors of the $\mathrm{MI}$ up to a maximum temperature of $1360^{\circ} \mathrm{C}$. In most of the experiments, the Ml were homogenized completely (without crystals or bubbles) and remained homogeneous during quenching to room temperature. The resulting single phase MI contained a homogeneous glass phase. These tests demonstrate the applicability of the Linkam TS1400XY microscope heating stage to homogenize and quench MI to produce homogeneous glasses that can be analyzed with various techniques such as Electron Microprobe (EMP), Secondary Ion Mass Spectrometry (SIMS), Laser ablation Inductively Coupled Plasma Mass Spectrometry (LA ICP-MS), Raman spectroscopy, FTIR spectroscopy, etc.

During heating experiments, the optical quality varied greatly between samples and was a function of not only the temperature of observation, but also on the amount of matrix glass attached to the phenocryst, the presence of other $\mathrm{MI}$ in the sample which are connected to the outside of the crystal, and the existence of mineral inclusions in the host.

Keywords: microscope heating stage $\cdot$ melt inclusion $\bullet$ microthermometry $\bullet$ volatiles
(c) Versita sp. z o.o. 


\section{Introduction}

Melt inclusions provide perhaps the most direct method to study magmatic processes and the evolution of magmatic systems [1,2], and the number of publications that mention melt inclusions has increased dramatically in recent years [3]. In fact, the only direct way to determine the volatile content of the melt in a magma body before an eruption is by measuring the volatile contents in $\mathrm{MI}$. It is widely accepted that the concentration of volatiles $\left(\mathrm{H}_{2} \mathrm{O}\right.$, $\mathrm{CO}_{2}, \mathrm{SO}_{2}$, etc.) in a magma chamber beneath a volcano determines the magnitude and style of the volcanic eruption, and many studies have focused on measurement of the volatiles in $\mathrm{MI}[1,4]$. These analyses assume that the $\mathrm{Ml}$ represents the quenched melt that was trapped at magmatic conditions and has undergone no changes during cooling. Depending on the $\mathrm{Ml}$ pressure-temperature path before and during natural quenching [5-8], the MI may partially or totally crystallize, and/or some of the volatiles that were originally dissolved in the melt may exsolve during cooling to form a vapor bubble. Some volatiles may also diffuse out of the MI following trapping, but this process is beyond the scope of this study and is not discussed further.

Depending on the type of information sought and the analytical technique to be used (e.g., electron microprobe analysis, EMP, or secondary ion mass spectrometry, SIMS), it may be necessary to re-homogenize the MI before analysis in order to obtain compositional data that are representative of the melt at the time of trapping. Various techniques have been used to successfully homogenize MI, including heating in one-atmosphere furnaces [9-12], heating in high-pressure (cold-seal or internally-heated) vessels [13-16], heating in piston cylinder apparatus [17$19]$, and heating in a microscope-mounted high temperature stage $[8,9,20-23]$. Each of these techniques has advantages and disadvantages, as described by [15, 24].

One of the major advantages of using a microscopemounted heating stage to homogenize $\mathrm{MI}$ is that the $\mathrm{Ml}$ can be observed continuously during heating from room temperature to homogenization. This approach allows information such as the temperature of first melting and the temperatures (and order) of disappearance of various phases to be observed and measured (Fig. 1 in [15]), and prevents overheating of the MI because heating can be stopped at the moment of homogenization. Importantly, homogenization of the Ml using a microscope mounted heating stage allows workers to determine if phases present after quenching represent phases that were still present at the highest temperature to which the $\mathrm{MI}$ were heated, or if they represent phases that nucleated from the melt during quenching. This information is critical to understanding whether or not the MI trapped a single melt phase, if heating rates were sufficiently slow to maintain equilibrium between the phases in the $\mathrm{MI}$, and if quenching rates were sufficiently fast to prevent new phases (crystals and vapor bubbles) from nucleating during cooling. As described in [7, 8, 25], in order to rehomogenize the melt to obtain the original volatile content of $\mathrm{MI}$, many researchers have used a heating stage with a rapid quenching system mounted on an optical microscope (e.g. the Vernadsky stage, [26]). Some earlier high temperature stages, such as the Linkam TH1500 which was the precursor model to the stage described here, offered only relatively slow cooling by turning off power to the heater. In this and similar stages, it was often not possible to quench the MI without significant crystallization on the walls, or without crystallizing daughter minerals or nucleating a vapor bubble in the inclusion.

In this study, several experiments have been performed using the new Linkam TS1400XY heating stage to assess its suitability for the homogenization of $\mathrm{Ml}$ and subsequent quenching of the homogeneous melt to a glass, and the examination of the optical viewing quality during these processes at elevated temperature. Samples studied are from the Toba Tuff eruption (Sumatra), from the Solchiaro eruption on the Island of Procida (Southern Italy), and from the Sarno eruption at Monte Somma-Vesuvius (Southern Italy). The geology and petrologic characteristics of the Toba Tuff [27-29], Solchairo eruption [30] (and references therein) and the Sarno eruption [31, 32] have been described previously, and the interested reader is referred to these sources for additional information.

The three samples used for this study were gently crushed using a wooden pestle to avoid damaging phenocrysts, and crystals were selected and mounted on glass bars and polished using the method described by [33]. Quartz phenocrysts were selected from pumice fragments of the Toba Tuff deposits, olivine and clinopyroxene phenocrysts were extracted from scoria ejected from the Solchiaro volcano, and finally clinopyroxene crystals were selected from nodules of the Sarno eruption. Only crystals containing partially or totally recrystallized MI were selected.

\section{Description of the hardware and analytical conditions}

The Linkam TS1400XY heating stage (Fig. 1a, c) consists of a platinum winding encased in ceramic (Fig. $1 \mathrm{~b}$ ) to produce a tube furnace that is large enough to accommodate $5 \mathrm{~mm} \times 5 \mathrm{~mm}$ samples with a thickness of up to $\approx 0.5 \mathrm{~mm}$. If inert gas is not circulated through the furnace during heating, the highest temperature achievable is $1400^{\circ} \mathrm{C}$; 
however, we highly recommend that inert gas is circulated through the furnace during operation, especially for iron-bearing host phases, as described below.

The temperature inside the furnace of the Linkam TS1400XY stage is controlled by the T95-LinkPad system controller that includes a touch-screen controller, which can be operated with either a stylus or using one's fingers (Fig. 1d). With this digital controller, the temperature can be regulated manually, similar to other microscopemounted heating stages, but can also be programmed before each experiment with a known and constant heating rate. Ramps can also be programmed, whereby the sample is held at a temperature for some period of time before heating is continued, as was described by [12]. During heating experiments, a constant flow of an inert gas is usually introduced into the heating stage to prevent oxidation of the analyzed sample [24]. If $\mathrm{He}$ is circulated through the furnace to avoid oxidation of the sample at high temperature, the highest temperature reached during heating experiments was $1260^{\circ} \mathrm{C}$. If $\mathrm{Ar}$ is circulated through the stage instead of $\mathrm{He}$, the highest temperature achieved during heating experiments was $1360^{\circ} \mathrm{C}$. In this study, we used $\mathrm{Ar}$ gas at a flow rate of $0.5( \pm 5 \%)$ liter/min to prevent oxidation. With these conditions, even though we programmed the stage to go to a temperature higher than $1360^{\circ} \mathrm{C}$, the temperature "plateaued" at $\approx 1360^{\circ} \mathrm{C}$. Before each experiment, the heating stage was calibrated using the melting temperatures of $\mathrm{NaCl}\left(801^{\circ} \mathrm{C}\right)$ and $\mathrm{Au}$ $\left(1064.2^{\circ} \mathrm{C}\right)$. The difference between the known melting temperatures of the calibration standards and the measured temperature was always $<10^{\circ} \mathrm{C}$.

Samples are placed on a sapphire plate that is mechanically connected to a metal frame which allows the sample to be moved into and out of the furnace (see Fig. 1b). Once the sample is inserted into the ceramic tube furnace and the lid is placed on to the stage, the sapphire plate can be moved $\approx 6 \mathrm{~mm}$ in the $X$ and $Y$ directions to locate and monitor inclusions during heating. The earlier version of this stage, the Linkam TH1500, did not permit the sample to be moved in the $X$ and $Y$ directions after the lid was placed onto the stage. The Linkam TS1400XY heating stage is provided with a spring mechanism connected to the sapphire slide (Fig. 1a, 1c). The spring mechanism allows the user to remove the crystal from the ceramic furnace rapidly to quench the $\mathrm{Ml}$ after homogenization is achieved. When the sample is removed from the furnace using this technique, it is placed on top of a water cooled metallic platform that reduces the sample temperature to a few hundred degrees in a few seconds. The quench rate with the Linkam TS1400XY stage was determined to be $\approx 240^{\circ} \mathrm{C} / \mathrm{s}$ from 1400 to $800^{\circ} \mathrm{C}$, and $\approx 230^{\circ} \mathrm{C} / \mathrm{s}$ from 1400 to $600^{\circ} \mathrm{C}$, based on numerous quenching tests. This quench rate is slower than that reported for the Vernadsky stage (1-2 seconds to quench from as high as $1500^{\circ} \mathrm{C}$ to room temperature [26]), but was fast enough to quench the $\mathrm{MI}$ tested in this study. The heating rates that can be accommodated by the Linkam TS1400XY range from 1 to $200^{\circ} \mathrm{C} / \mathrm{min}$.

Various workers used different heating rates and protocols (continuous versus stepped heating) to homogenize silicate melt inclusions and it does not appear that any single rate or method is applicable to all MI in all different host phases. The method that is most appropriate for a given set of $\mathrm{MI}$ should be established based on kinetic experiments [5] that consist of heating (followed by cooling) the same $\mathrm{Ml}$ at different heating rates (from faster to slower), and recording the homogenization temperature for each heating rate. As reported in Fig. 2 by [5], in kinetic experiments, the homogenization temperature decreases with decreasing heating rate until, eventually, the homogenization temperature approaches a constant value, even though the heating rate decreases. For each host phase, the "correct" heating rate is that which corresponds to the heating rate at which the homogenization temperature becomes constant. When faster heating rates are used, the recorded homogenization temperature will be higher compared to the homogenization temperature determined with slower heating rates $\left(\sim 40^{\circ} \mathrm{C}\right.$ difference in Fig. 2 by [5]). However, when slower heating rates are used, the likelihood that the Ml composition will be modified by diffusion of components into or out of the Ml increases [24]. A complete discussion of the procedure to determine the "correct" heating rates and homogenization temperatures is beyond the scope of this study, and the reader is referred to $[5,12]$. We did not perform kinetic experiments on the $\mathrm{Ml}$ in this study because the goal of the study was not to determine the "correct" homogenization temperature. The goal was to examine the behavior of Ml during heating to produce a homogeneous melt phase, and to determine if the homogenized $\mathrm{Ml}$ could be quenched quickly enough to maintain a homogeneous melt (glass) to ambient conditions, without the formation of a vapor bubble or crystals. The heating schedules used for heating experiments on crystals from the samples studied are reported in Table 1. It should be noted that the heating rates used in this study (Table 1) are comparable to heating rates used by other workers $\left(1\right.$ to $3^{\circ} \mathrm{C} / \mathrm{min}$ near the homogenization temperature $[12,16,34])$. In some cases, after homogenization, the temperature was held constant for about 10 minutes to photograph the $\mathrm{Ml}$ before quenching.

For the experiments described here, the Linkam TS1400XY was mounted on an Olympus BX60 petrographic microscope and 10X and 40X objective lenses were used for viewing and photographing the inclusions. 


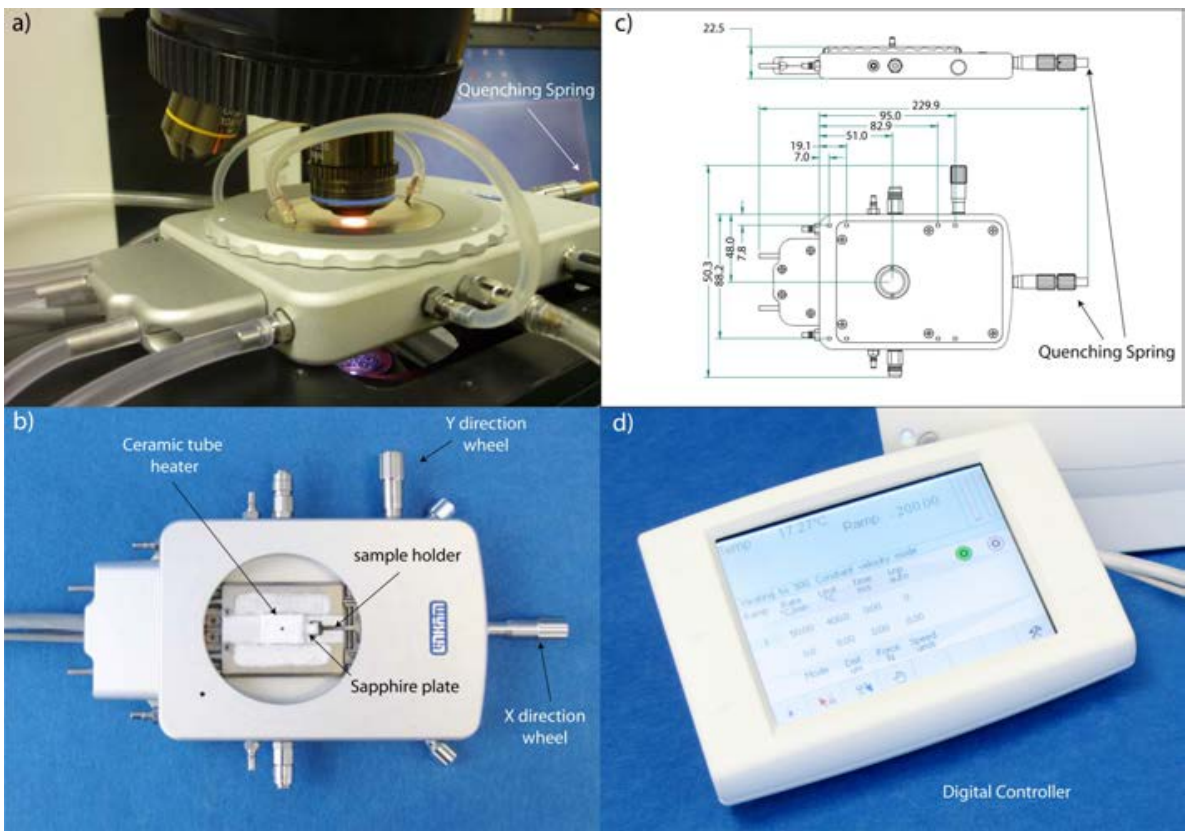

Figure 1. The Linkam TS1400XY heating stage. 1a) The Linkam TS1400XY stage mounted on a microscope during a heating experiment, with the temperature at $\approx 1350^{\circ} \mathrm{C}$. The quenching spring is on the right side of the heating stage as indicated by the arrow. The bright spot immediately beneath the objective lens is the reddish glow from the furnace at this high temperature. 1b) The Linkam TS1400XY with the lid opened. It is possible to observe the ceramic furnace, the sapphire plate with the metallic frame, and the XY control wheels. This photo is modified from: http://www.mccronemicroscopes.com/store/catalog.asp?item=356\&categoryid=48.1c) Technical drawing of the Linkam TS1400XY heating stage. All the measurements reported are in $\mathrm{mm}$. Important to note is the quenching spring connected to the X-direction wheel (courtesy of V. Kamp). 1d) T95-LinkPad system controller. Additional technical information and images are available at the Linkam website (http://www.linkam.co.uk/).

Table 1. Heating schedule used for experiments on crystals from the Solchiaro, Sarno and Toba Tuff eruptions.

\begin{tabular}{|c|c|c|}
\hline Temperature $^{\circ} \mathrm{C}$ & Heating rate ${ }^{\circ} \mathrm{C} / \mathrm{min}$ & sample \\
\hline $25-900$ & 100 & Solchiaro and Sarno \\
$900-1000$ & 50 & Solchiaro and Sarno \\
$1000-1100$ & 25 & Solchiaro and Sarno \\
$1100-1200$ & 10 & Solchiaro and Sarno \\
$1200-1360$ & 5 & Solchiaro and Sarno \\
\hline $25-600$ & 100 & Toba Tuff \\
$600-700$ & 50 & Toba Tuff \\
$700-800$ & 25 & Toba Tuff \\
$800-850$ & 10 & Toba Tuff \\
$850-1000$ & 5 & Toba Tuff \\
\hline
\end{tabular}

\section{Results}

In most of the experiments described here, it was possible to completely homogenize the MI and, importantly, to quench the melt to a homogeneous glass after homogenization (Figs. 2-5). A few of the Ml could not be heated to homogenization, either because the optics deteriorated before homogenization was achieved or, in one case, because the crystals began to fracture and break into smaller pieces owing to the high internal pressures generated in the volatile-rich $\mathrm{Ml}$ during heating. For such samples, it is necessary to heat the $\mathrm{Ml}$ in a pressurized vessel to eliminate or minimize decrepitation and/or leakage $[14,15,24,35]$.

In experiments performed on crystallized $\mathrm{MI}$ in quartz from the Toba Tuff in Sumatra, it was always possible to completely homogenize and quench the $\mathrm{MI}$ to a bubble-free, homogeneous glass (Fig. 2). More importantly, during the heating experiment, the $\mathrm{Ml}$ behavior was easy to monitor because the viewing optics remained very good up to the highest temperature required for homogenization $\left(<1000^{\circ} \mathrm{C}\right)$ (Fig. 2). The behavior of the $\mathrm{Ml}$ in quartz from the Toba Tuff is expected to be characteristic of $\mathrm{Ml}$ in quartz from most environments, based on the cumulative experiences of the investigators in this study.

$\mathrm{MI}$ in olivine and clinopyroxene from the Solchiaro eruption on Procida Island (Southern Italy) commonly contain one or more solid phases as well as one or more vapor bubbles. These MI homogenized between 1060 and $1340^{\circ} \mathrm{C}$. A range in temperatures could be related to several factors. It is well known that there is a positive correlation between the size of the $\mathrm{Ml}$ and the temperature 


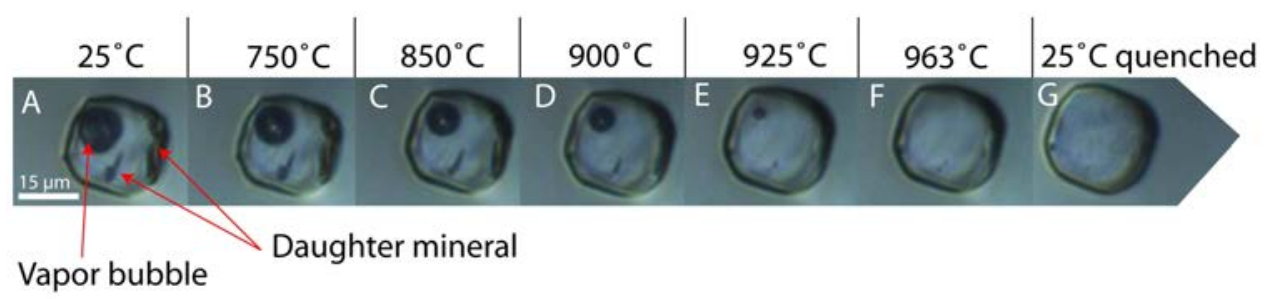

Figure 2. Heating experiment performed on quartz phenocryst from the Toba Tuff eruption in Sumatra. The Ml is around $15 \mu \mathrm{m}$ in diameter and has a sub-rectangular shape. A) At room temperature $\left(25^{\circ} \mathrm{C}\right)$, the $\mathrm{Ml}$ contains one vapor bubble and three unidentified daughter crystals. From $\mathrm{B}$ to $\mathrm{E}$ ) From $750^{\circ} \mathrm{C}$ to $925^{\circ} \mathrm{C}$ the volumes of the vapor bubble and of the three daughter crystals progressively decrease as these phases dissolve back into the melt. F) At $963^{\circ} \mathrm{C}$ the MI consists of only a homogeneous silicate melt phase. G) The Ml contains a homogenous glass at ambient conditions after quenching from $963^{\circ} \mathrm{C}$.

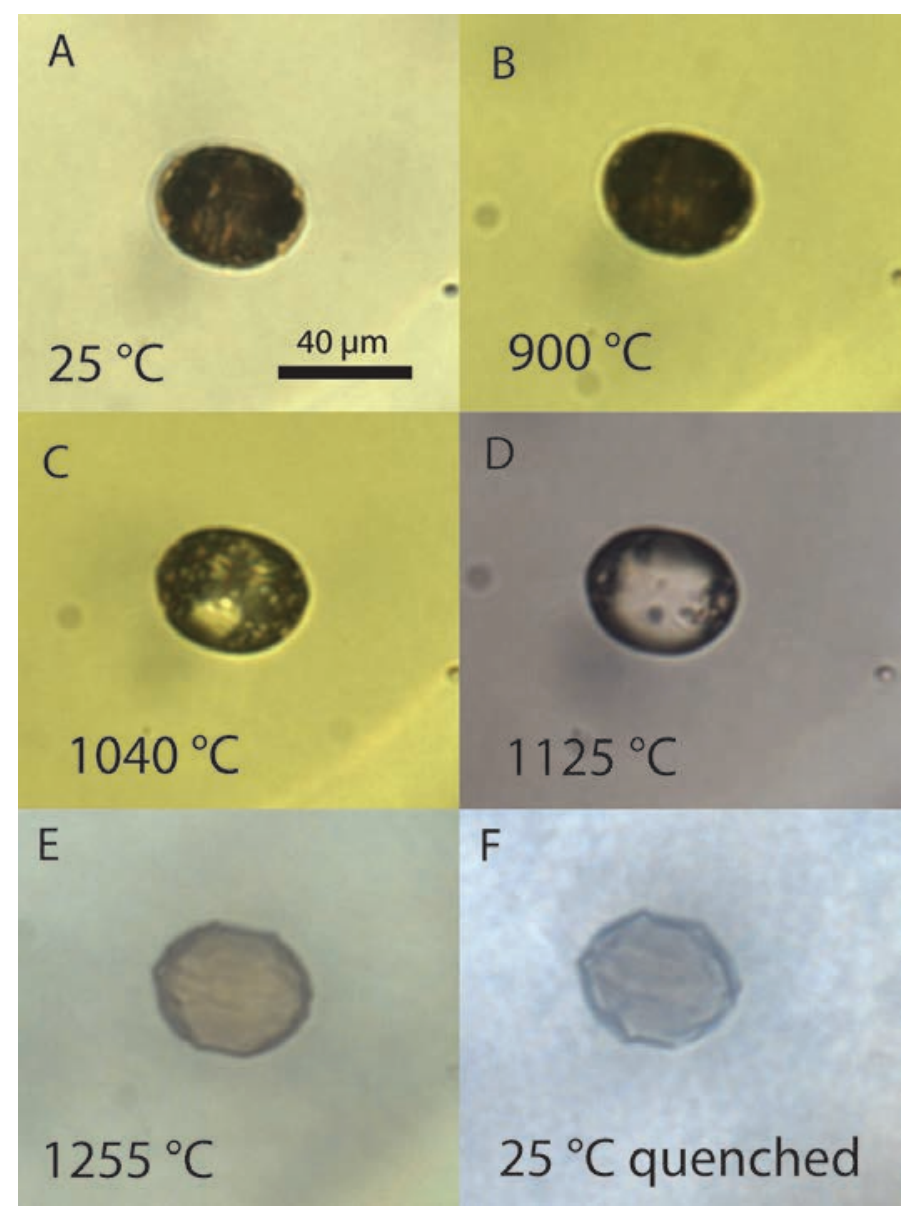

Figure 3. Heating experiment performed on $\mathrm{Ml}$ in an olivine phenocryst from scoriae of the Solchiaro eruption of the Phlegrean Volcanic District (PVD) in Southern Italy. The MI has an ellipsoidal shape. A) At room temperature $\left(25^{\circ} \mathrm{C}\right)$, the $\mathrm{Ml}$ is partially crystallized and nearly opaque. Some daughter crystals are visible at the olivine host - melt inclusion interface. B) At $900^{\circ} \mathrm{C}$, daughter crystals at the olivine/inclusion interface are smaller relative to those at room temperature. C) At $1040^{\circ} \mathrm{C}$ it is possible to observe some vapor bubbles, solid and melt phases. D) At $1125^{\circ} \mathrm{C}$ most of the melt inclusion consists of a silicate melt phase. E) At $1255^{\circ} \mathrm{C}$ the $\mathrm{Ml}$ is completely homogenized and contains only a melt phase. Note that at this temperature the Ml assumes a negative crystal shape. Also, the "wrinkles" at the melt/crystal interface may indicate that the MI was overheated and that the host phase has begun to melt. F) After quenching from $>1260^{\circ} \mathrm{C}$ to ambient temperature the Ml contains a homogenous glass. During the quenching, some crystallization of olivine at the olivine/glass interface may have occurred. 


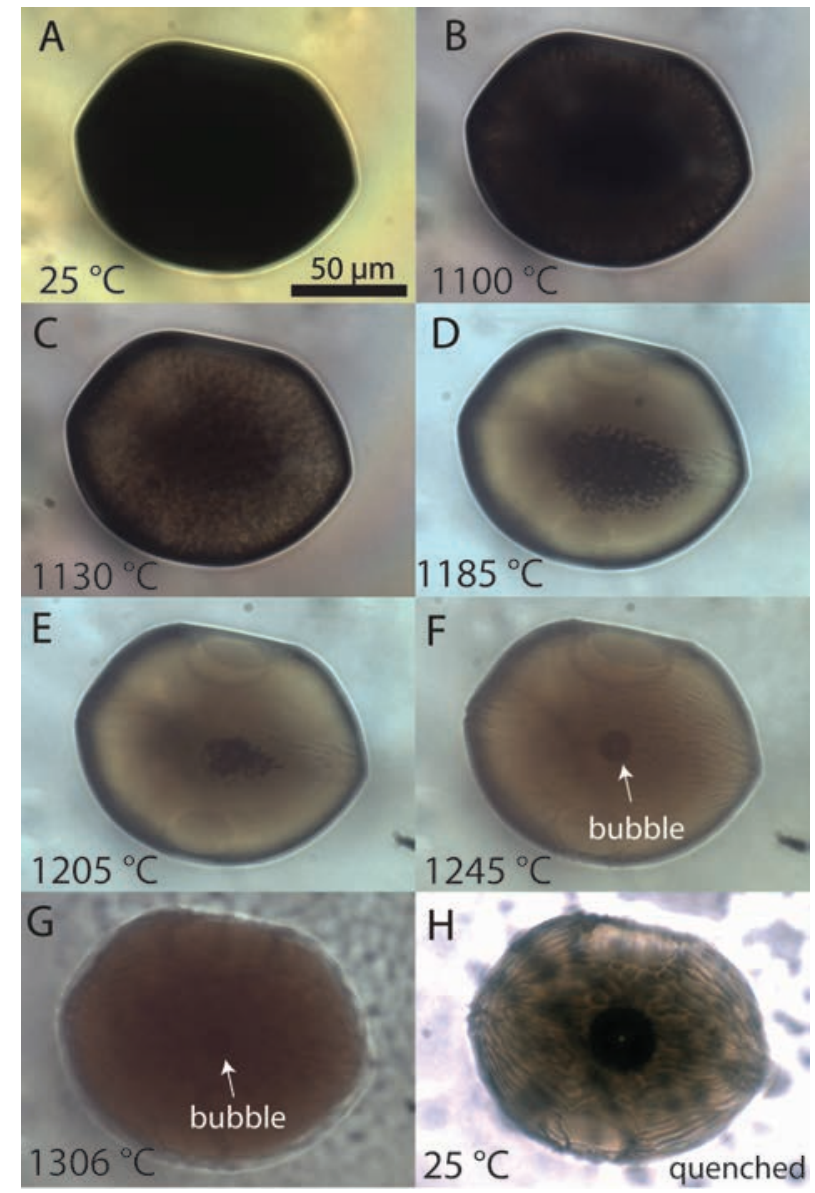

Figure 4. Heating experiment performed on Ml contained in an olivine phenocryst from scoriae of the Solchiaro eruption of the Phlegrean Volcanic District (PVD) in Southern Italy. The MI has a sub-negative crystal shape with smooth olivine/inclusion interface. A) At room temperature $\left(25^{\circ} \mathrm{C}\right)$, the $\mathrm{Ml}$ is totally crystallized and may be mis-identified as an opaque solid inclusion (e.g., spinel) during petrographic examination. There are no features visible to suggest that this is a melt inclusion. B) At $1110^{\circ} \mathrm{C}$ a melt phase can be observed near the olivine/MI interface. The inner part of the Ml remains dark. C) As the temperature increases (e.g., $1130^{\circ} \mathrm{C}$ ), the melt region expands toward the center of the MI. D) At $1185^{\circ} \mathrm{C}$ the black spots in the interior of the $\mathrm{Ml}$ appear to assemble to form larger vapor bubbles. The MI tends to a more negative crystal shape as the temperature increases. E) At $1205^{\circ} \mathrm{C}$ a few vapor bubbles are observed and most of the $\mathrm{Ml}$ consists of silicate melt. F) At $1245^{\circ} \mathrm{C}$ the Ml consists of silicate melt and a single vapor bubble in the center of the Ml. G) During heating from 1300 to $1340^{\circ} \mathrm{C}$ the bubble does not dissolve into the melt and the bubble size does not change. At $1340^{\circ} \mathrm{C}$ the $\mathrm{Ml}$ was no longer visible as the field of view became dark and with a reddish glow. H) After quenching from $1340^{\circ} \mathrm{C}$ to room temperature, the $\mathrm{Ml}$ contains a homogenous glass plus a vapor bubble that is likely of primary origin. Note the difference between the Ml before the experiment and after quenching. The glass composition can be analyzed for major, trace and volatile elements, while the bubble can be analyzed for volatiles using Raman spectrometry.

of homogenization, because the larger the inclusion, the greater the energy necessary to melt the crystal around the $\mathrm{MI}$ [7]. However, in these experiments there was no correlation between the size of $\mathrm{Ml}$ and the temperature of homogenization, suggesting that $\mathrm{Ml}$ size was not responsible for this temperature range. Rather, the temperature range reflects differences in melt composition reflecting trapping at different times during evolution of the magma. Thus, more primitive $\mathrm{Ml}$ entrapped in more primitive olivine/clinopyroxene show homogenization temperatures that are much higher than $\mathrm{Ml}$ entrapped in more evolved phenocrysts (e.g., Fo-poor olivine) [30]. Further- more, phenocrysts may not be linked genetically and thus $\mathrm{Ml}$ analyzed may have formed in totally different environments within the magma body, and/or at different times. For this study, petrographic analysis of the phenocrysts and $\mathrm{Ml}$ was not conducted because the purpose of this study was not to determine a melt petrogenesis, but rather, to test suitability of the Linkam stage for homogenizing and quenching $\mathrm{MI}$.

Some experiments on recrystallized MI from Solchiaro produced homogeneous glassy $\mathrm{Ml}$ with no vapor bubble (Fig. 3) after quenching from high temperature (1060 to $\sim 1300^{\circ} \mathrm{C}$ ). In a few experiments, the sample was heated to 
approximately $1340^{\circ} \mathrm{C}$ but complete homogenization was not achieved. During heating to that temperature, the field of view became progressively darker and a reddish glow developed, making it difficult to observe the behavior of the $\mathrm{Ml}$ during continued heating. Darkening and development of the reddish glow generally became noticeable and caused the optics to degrade to the point where the $\mathrm{Ml}$ could no longer be observed over a temperature range of about $50^{\circ} \mathrm{C}$. At lower temperatures, the optics were generally excellent, with the quality of the optics depending mostly on two factors: the thickness of the phenocryst and the relative area of the sample represented by solid and/or melt inclusions, with the optical quality being inversely related to the inclusion content. Also, the optics improved if the crystal was free of matrix glass. As previously noted by [15], groundmass adhering to phenocrysts affects the optics because it consists of dark recrystallized glass that generally melts before the $\mathrm{Ml}$ has completely homogenized and flows around the crystal (or through fractures in the crystal) causing the optics to deteriorate. In order to remove matrix glass from the crystals before heating experiments, some authors have suggested that the samples should be placed in concentrated hydrofluoric acid solution for several seconds $[15,36]$, but this was not done for the phenocrysts studied here.

In some cases, the MI were heated to relatively high temperature and all of the solids in the Ml melted, but the vapor bubble did not completely dissolve back into the melt before the optics deteriorated and it was no longer possible to observe the $\mathrm{Ml}$ behavior. When the $\mathrm{MI}$ was quenched from a temperature slightly higher than that at which the $\mathrm{Ml}$ could no longer be observed (blind quenching), the single bubble that (presumably) remained in the $\mathrm{MI}$ grew larger as the Ml cooled due to the effect of the greater thermal contraction of the melt relative to the host (Fig. 4). Because the Ml could not be observed to the point of complete vapor bubble disappearance, it is not clear if the bubble did indeed disappear but renucleated during cooling, or if the bubble never completely disappeared and simply grew larger during cooling. Moreover, the bubble in these MI may represent a trapped vapor bubble (i.e., the MI trapped a volatile-saturated melt plus a vapor bubble) and, thus, the bubble should not be expected to dissolve back into the melt. Another interpretation (especially for relatively larger MI) could be that the internal pressure in the $\mathrm{MI}$ is now less than the internal pressure at the moment of the entrapment owing to the compressibility of the host phase. Because the host phase is heated at one atmosphere pressure during the experiments, the confining pressure is lower than the pressure at which the phenocryst trapped the MI. Therefore, the volume of the host phase, and the "cavity" represented by the

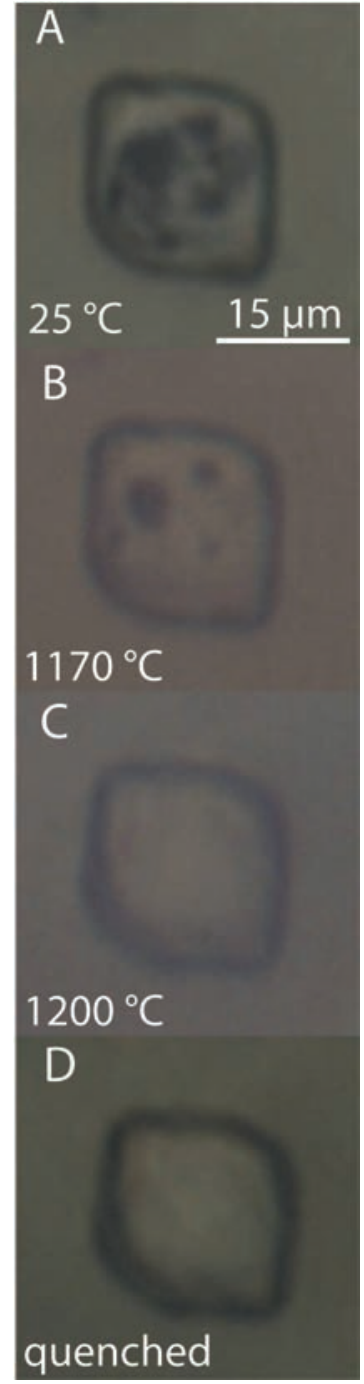

Figure 5. Heating experiment performed on a melt inclusion in clinopyroxene from a nodule from the Sarno eruption at Mt Somma-Vesuvius in Southern Italy. The Sarno eruption is considered to be the largest volume eruption in the history of Somma-Vesuvius [31]. A) At room temperature $\left(25^{\circ} \mathrm{C}\right)$, the MI is partially crystallized. Some daughter crystals or vapor bubbles are visible. B) At $1170^{\circ} \mathrm{C}$ the size of the daughter crystals/vapor bubbles has decreased significantly. C) At $1200^{\circ} \mathrm{C}$ Ml contains only silicate melt. F) After quenching from $1200^{\circ} \mathrm{C}$ to room temperature, the $\mathrm{MI}$ contains a homogenous glass.

MI, is slightly greater than that at the time of trapping, resulting in lower internal pressure in the $\mathrm{MI}$ during laboratory heating and, concomitantly, lower volatile solubility in the melt phase. A final explanation for the fact that the bubble remained at the highest temperature to which the $\mathrm{Ml}$ could be heated and observed is that the actual homogenization temperature is higher than this temperature. However, in our experiment, the latter interpretation 
is unlikely owing to the widespread melting of the host observed at these high temperatures (e.g., $>1320^{\circ} \mathrm{C}$ ).

In half of the experiments performed on clinopyroxenehosted, recrystallized $\mathrm{Ml}$ from nodules from the Sarno eruption of Monte Somma-Vesuvius (Southern Italy), it was possible to quench the $\mathrm{Ml}$ to a homogeneous glass without re-nucleating vapor bubbles (Fig. 5). Similar to samples from Solchiaro, some of the MI could not be monitored completely up to the temperature of homogenization owing to the deterioration of the optics above a certain temperature. Crystals from the Sarno eruption are rich in solid and recrystallized MI. For this reason, the optics deteriorated at a lower temperature, compared to the experiments performed on olivines from Solchiaro, which contain relatively few melt and solid inclusions. For the Sarno clinopyroxene-hosted $\mathrm{Ml}$, the optics remained relatively good up to $\approx 1260^{\circ} \mathrm{C}$; above this temperature they deteriorated rapidly with further heating.

\section{Discussion of advantages and limitations of the Linkam TS1400XY stage}

The most important advantage of using a microscopemounted heating stage (such as the Linkam TS1400XY) relative to one atmosphere furnaces and high pressure autoclaves is that the $\mathrm{Ml}$ can be observed continuously during the heating/cooling experiments [15]. For example, the appearance/disappearance of a microscopically recognizable phase is possible during heating experiments using these types of devices, but is not possible when the $\mathrm{Ml}$ is heated in a furnace. Also, the temperatures at which phase changes occur in the $\mathrm{Ml}$ can be determined with better precision using a microscope-mounted heating stage, compared to a large volume furnace. As noted by [15] the ability to monitor the behavior of MI from the Red Mountain, Arizona, porphyry copper deposit continuously during heating, made it possible for those workers to determine that quartz, plagioclase and probably apatite were three minerals on the liquidus when the melt inclusions were trapped, and that the melt was $\mathrm{H}_{2} \mathrm{O}$-saturated. These workers were also able to distinguish between $\mathrm{MI}$ that trapped only a melt phase, and those that trapped melt \pm crystals \pm vapor, and to eliminate those $\mathrm{Ml}$ that trapped multiple phases from any subsequent analyses.

Compared to some other microscope-mounted heating stages, the Linkam TS1400XY stage offers several advantages. Firstly, the Linkam TS1400XY heating stage is a "turn key" digitally controlled system (e.g., the T95LinkPad; see Fig. 1d), while some other heating stages require the user to design and build a system to control and monitor the temperature. Thus, compared to some other commercially available stages, the Linkam system may be better for someone who does not have access to machining and/or electronics facilities. The digitally controlled system allows one to set heating/cooling cycles, which, as described above, can be used to establish heating rates to determine the "correct" temperature of homogenization. These cycles adopted during kinetic experiments are easier to perform when the heating rates are controlled electronically rather than manually. Secondly, we found it easier to load crystals into the furnace of the Linkam TS1400XY stage than it is to load crystals into the somewhat confined platinum furnace of the Vernadsky stage. Thirdly, the position of the crystal under the microscope can be moved during the heating experiment without the need to move the entire heating stage. In this way, more $\mathrm{Ml}$ in a single grain can be monitored while viewing the sample at high magnification during heating experiments by moving the crystal in $X-Y$ space during observation. Finally, in the Vernadsky stage the analyzed crystal is placed onto a metal frame and thus photography during the heating experiment may be compromised, while in the Linkam TS1400XY stage the analyzed crystal sits on a sapphire slide which is transparent to light, resulting in relatively good optics during most of the heating sequence.

As reported above, even though the quench rate with the Linkam TS1400XY stage is slower than that of the Vernadsky stage $\left(\approx 240^{\circ} \mathrm{C} / \mathrm{s}\right.$ from 1400 to $800^{\circ} \mathrm{C}$, and $\approx 230^{\circ} \mathrm{C} / \mathrm{s}$ from 1400 to $600^{\circ} \mathrm{C}$ ), the quenching rate was fast enough to quench the $\mathrm{MI}$ tested in this study. The most significant limitation of the Linkam TS1400XY heating stage identified in this study is the poor visibility that sometimes results during high temperature operation. This effect was not observed for Ml hosted in quartz, but was only observed with olivine and pyroxene-hosted MI that require higher temperatures to achieve homogenization. In our experiments involving olivine from Solchiaro, the optics degraded to the point where the $\mathrm{Ml}$ were not recognizable at a temperature around $1340^{\circ} \mathrm{C}$. For experiments on clinopyroxene from the Sarno eruption, the visibility deteriorated to the point that it was not possible to observe the behavior of $\mathrm{Ml}$ at a temperature around $1260^{\circ} \mathrm{C}$. In most cases, the deterioration in the optics was manifested by the sample becoming darker and with a reddish glow that increased in intensity as the temperature increased. The deterioration in optical quality during heating $\mathrm{Ml}$ in olivine and clinopyroxene is influenced by (1) the presence of matrix glass adhering to the phenocryst, (2) the presence of $\mathrm{Ml}$ connected (open) to the crystal surface, because they may "boil" during heating, releasing melt to the outside of the crystal, and (3) the high abundance 
of solid/melt inclusions in the sample. In addition, we noticed that the optics improved as the sample became thinner. Our observations suggest that during heating the infrared energy ("light") generated by the hot furnace ceramic is reflected in all directions, leading to deterioration in the optics during high temperature experiments. The presence of matrix glass, solid and melt inclusions in the sample, and melt on the exterior of the crystal all serve to enhance this reflection. If a microscope-mounted digital camera is used during heating experiments, the visibility may be improved. Also, the optical issue may be solved in the future by using a confocal method of observation (e.g., spinning disc or laser confocal; V. Kamp, personal communication). In addition, it should be emphasized that the degradation of the optics at a high temperature is not unique to the Linkam TS1400XY heating stage, but also occurs with the Vernadsky stage (and probably with other high temperature microscope stages). The effect is less significant in the Vernadsky stage because of the smaller size of the furnace and because the sample is not encased (or surrounded) by ceramic material.

In summary, the following suggestions can be adopted in order to improve the optical quality during heating experiments using the Linkam TS1400XY. First of all, as much of the matrix glass as possible should be removed from the crystals before heating experiments are conducted (e.g., using concentrated hydrofluoric acid solution as suggested by $[15,36])$. Secondly, the host crystals should be as thin as possible because, as explained above, less material reflects less light (infrared energy) generated in the furnace at high temperature. Thirdly, a microscope-mounted digital camera should be used to improve the visibility, especially at high temperature when it becomes difficult to make any observation looking through the microscope lens. Finally, the optics may be improved by using a different optical imaging technique, such as confocal spinning disk or a confocal laser scanning microscope.

\section{Summary}

Tests confirm that the Linkam TS1400XY heating stage is capable of heating $\mathrm{MI}$ to homogenization and quenching to produce a homogenous glass. This method produces glassy MI that can be analyzed using various microanalytical techniques that require a single, homogeneous phase for quantitative analysis to determine the compositions (especially the volatile contents) of the pre-eruptive melt. Experiments performed on recrystallized $\mathrm{Ml}$ that homogenize at less than $\sim 1100^{\circ} \mathrm{C}$ are optimal for observing the heating/cooling behavior of MI. Thus, for felsic melts and most intermediate composition melts, optical conditions during heating/cooling experiments are generally quite good. For mafic melt compositions, or samples with crystals that are rich in matrix glass, or contain opened Ml or mineral inclusions, the optical quality may deteriorate to the point where the inclusion is no longer visible during heating experiments, and cannot be observed to complete homogenization.

\section{Acknowledgements}

We would like to thank the Linkam Group for providing the opportunity to test the functions of the Linkam TS1400XY heating stage, in particular Jeff D. McGinn and Vincent Kamp. We also thank Matthew Steele-Maclnnis and Pilar Lecumberri Sanchez for discussions on the topic and editorial assistance. This material is based upon work supported by the National Science Foundation under grant no. EAR-1019770.

\section{References}

[1] Métrich N., Wallace P.J., Volatile abundances in basaltic magmas and their degassing paths tracked by melt inclusions. In: Putirka K.D.and Tepley F.J., Minerals, Inclusions and Volcanic Processes. Rev. Mineral. Geochem., 2008, 69, 363-402

[2] Sobolev A.V., Hofmann A.W., Jochum K.P., Kuzmin D.V., Stoll B., A young source for the Hawaiian plume. $\mathrm{Na}-$ ture, 2011, 476, 434-437

[3] De Vivo B., and Bodnar, R.J., Melt inclusions in volcanic systems. Elsevier Science, the Netherlands, 2003

[4] Helo C., Longpre M.A., Shimizu N., Clague D.A., Stix J., Explosive eruptions at mid-ocean ridges driven by $\mathrm{CO}_{2}$-rich magmas. Nat. Geosci., 2011, 4, 260-263

[5] Danyushevsky L.V., McNeill A.W., Sobolev A.V., Experimental and petrological studies of melt inclusions in phenocrysts from mantle-derived magmas: an overview of techniques, advantages and complications. Chem. Geol., 2002, 183, 5-24

[6] Lowenstern J.B., Applications of silicate-melt inclusions to the study of magmatic volatiles. In: Thompson J.F.H. (Ed.), Magmas, Fluids and Ore Deposits. Mineralogical Association of Canada, Short Course, Canada, 1995, 23, 71-99

[7] Roedder E., Origin and significance of magmatic inclusions. B. Mineral., 1979, 102, 487-510

[8] Sobolev A.V., Kostyuk V.P., Magmatic crystallization based on study of melt inclusions. In: Roedder E. (Ed.), Fluid Inclusion Research, Proceedings of COFFI, The University of Michigan Press, 1976, 9, 182-253 
[9] Fedele L., Bodnar R.J., DeVivo B., Tracy R., Melt inclusion geochemistry and computer modeling of trachyte petrogenesis at Ponza, Italy. Chem. Geol., 2003, 194, 81-104

[10] Nielsen R.L., Crum J., Bourgeois R., Hascall K., Forsythe L.M., Fisk M.R., Christie D.M., Melt inclusions in high-An plagioclase from the Gorda Ridge: an example of the local diversity of MORB parent magmas. Contrib. Mineral. Petr., 1995, 122, 34-50

[11] Sinton C.W., Christie D.M., Coombs V.L., Nielsen R.L., Fisk M.R., Near-primary melt inclusions in anorthite phenocrysts from the Galapagos Platfrom. Earth Planet. Sc. Lett., 1993, 119, 527-537

[12] Student J.J., Bodnar R.J., Synthetic Fluid Inclusions XIV: Coexisting Silicate Melt and Aqueous Fluid Inclusions in the Haplogranite- $\mathrm{H}_{2} \mathrm{O}-\mathrm{NaCl}-\mathrm{KCl}$ System. J. Petrol., 1999, 40, 1509-1525

[13] Anderson A.T., Davis A.M., Lu F., Evolution of Bishop Tuff Rhyolitic Magma Based on Melt and Magnetite Inclusions and Zoned Phenocrysts. J. Petrol., 2000, 41, 449-473

[14] Skirius C.M., Peterson J.W., Anderson A.T., Homogenizing Rhyolitic Glass Inclusions from the Bishop Tuff. Am. Mineral., 1990, 75, 1381-1398

[15] Student J.J., Bodnar R.J., Silicate melt inclusions in porphyry copper deposits: Identification and homogenization behavior. Can. Mineral., 2004, 42, 1583-1599

[16] Thomas J.B., Bodnar R.J., Shimizu N., Chesner C.A., Melt Inclusions in Zircon. Rev. Mineral. Geochem., 2003, 53, 63-87

[17] Bartoli O., Cesare B., Poli S., Bodnar R.J.., Frezzotti M.L., Acosta-Vigil A, Meli S., Melting in the deep crust: message from melt inclusions in peritectic garnet from migmatites. Mineral. Mag., 2011, 75, 495

[18] Cesare B., Acosta-Vigil A., Ferrero S., Bartoli O., Melt inclusions in migmatites and granulites. J. Virt. Expl., 2011, 40, n. 2, doi: 10.3809/jvirtex.2011.00268

[19] Ferrero S., Bartoli O., Cesare B., Salvioli-Mariani E., Acosta-Vigil A., Cavallo A., Groppo C., Battiston S., Microstructures of melt inclusions in anatectic metasedimentary rocks. J. Metamorph. Geol., 2012, doi: 10.1111/j.1525-1314.2011.00968.x

[20] Clocchiatti R., Les inclusions vitreuses des cristaux de quartz; Etude optique, thermo-optique et chimique; Applications geologiques. Vitreous inclusions in quartz crystals; optical, thermo-optical and chemical studies; geologic applications. Mem. S. Geo. F., no, 1975, 122

[21] Frezzotti M.L., Magmatic immiscibility and fluid phase evolution in the Mount Genis granite (southeastern Sardinia, Italy). Geochim. Cosmochim. Ac., 1992, 56, 21-33
[22] Lowenstern J.B., Dissolved Volatile Concentrations in an Ore-Forming Magma. Geology, 1994, 22, 893-896

[23] Reyf F.G., Direct evolution of W-rich brines from crystallizing melt within the Mariktikan granite pluton, west Transbaikalia. Miner. Deposita, 1997, 32, 475490

[24] Bodnar R.J., Student J.J., Melt inclusions in plutonic rocks: Petrography and microthermometry. In: Webster J.D. (Ed.), Melt Inclusions in Plutonic Rocks, Mineralogical Association of Canada, Short Course, Montreal, Quebec, 2006, 36, 1-25

[25] Schiano P., Primitive mantle magmas recorded as silicate melt inclusions in igneous minerals. Earth-Sci. Rev., 2003, 63, 121-144

[26] Sobolev A.V., Dmitriev L.V., Barsukov V.L., Nevsorov V.N., Slutsky A.B., The formation conditions of the high magnesium olivines from the monomineralic fraction of Luna 24 regolith. Proceedings of the $11^{\text {th }}$ Lunar and Planetary Science Conference, 1980, 105-116

[27] Beddoe-Stephens B., Aspden J.A., Shepherd T.J., Glass inclusions and melt compositions of the Toba Tuffs, northern Sumatra. Contrib. Mineral. Petr., 1983, 83, 278-287

[28] Newman S., Chesner C., Volatile compositions of glass inclusions from the $75 \mathrm{Ka}$ Toba Tuff, Sumatra. Paper presented at the 1989 annual meeting of the Geological Society of America, St. Louis, MO, US, November 6-9, 1989

[29] Chesner C.A., Petrogenesis of the Toba Tuffs, Sumatra, Indonesia. J. Petrol., 1998, 39, 397-438

[30] Esposito R., Bodnar R.J., Danyushevsky L., De Vivo B., Fedele L., Hunter J., Lima A., Shimizu N., Volatile Evolution of Magma Associated with the Solchiaro Eruption in the Phlegrean Volcanic District (Italy). J. Petrol., 2011, 52, 2431-2460

[31] Bertagnini A., Landi P., Rosi M., Vigliargio A., The Pomici di Base plinian eruption of Somma-Vesuvius. J. Volcanol. Geoth. Res., 1998, 83, 219-239

[32] Landi P., Bertagnini A., Rosi M., Chemical zoning and crystallization mechanisms in the magma chamber of the Pomici di Base plinian eruption of SommaVesuvius (Italy). Contrib. Mineral. Petr., 1999, 135, 179-197

[33] Thomas J.B., Bodnar R.J., A technique for mounting and polishing melt inclusions in small $(>1 \mathrm{~mm})$ crystals. Am. Mineral., 2002, 87, 1505-1508

[34] Sobolev A.V., Danyushevsky L.V., Dmitriev L.V., Sushchevskaya N.M., High-Alumina Magnesium Tholeiite as One of Primary Melts of Basalts of the Mid-Oceanic Ridges. Geokhimiya+, 1988, 15221528

[35] Severs M.J., Azbej T., Thomas J.B., Mandeville C.W., 
Jr., Bodnar R.J., Experimental determination of $\mathrm{H}_{2} \mathrm{O}$ loss from melt inclusions during laboratory heating. Chem. Geol., 2007, 237(3-4), 358-371

[36] Anderson A.T., Jr., Hourglass inclusions; theory and application to the Bishop rhyolitic tuff. Am. Mineral., 1991, 76, 530-547 